\title{
Oxidative Stress and Antioxidant Defenses in Plasma of Patients with Behçet's Disease
}

\author{
Kader Köse, Pakize DoĞan, Meral Aşçıơ̆lu*, \\ Kuddusi Erkiliç† and Özcan Aşçıơ̆Lu $\ddagger$ \\ Departments of Biochemistry, ${ }^{*}$ Physiology, ${ }^{\dagger}$ Ophthalmology, \\ and ${ }^{\ddagger}$ Dermatology Erciyes University, Faculty of Medicine \\ 38039 Kayseri, Turkey
}

\begin{abstract}
Köse, K., DoĞan, P., Aşçiơ̆LU, M., ERkiliģ, K. and Aşçiơ̆Lu, Ö. Oxidative Stress and Antioxidant Defenses in Plasma of Patients with Behçet's Disease. Tohoku J. Exp. Med., 1995, 176 (4), 239-248_ Plasma myeloperoxidase (MPO) and glutathione peroxidase (GSH-Px) activities, and malondialdehyde (MDA), ceruloplasmin (Cp), transferrin (TF), thiol (SH), selenium (Se) and copper $(\mathrm{Cu})$ levels were determined in patients with Behçet's disease (BD), in order to investigate whether the plasma antioxidant defense system is impaired in BD. When compared to controls, plasma MDA, $\mathrm{Cp}, \mathrm{Cu}$ levels and also plasma MPO activity were significantly higher in patients, whereas plasma TF, SH and Se levels, and also plasma GSH-Px activity were lower in BD patients than those in controls. In addition, there were significant and positive correlations between MDA-Cp, MDA-Cu, MDA-MPO, MPO-Cp, GSH-Px-Se, $\mathrm{Cp}-\mathrm{Cu}$, and TF-SH parameters, but negative correlations between MPO-TF and Cp-TF parameters in $\mathrm{BD}$ patients. Based on these findings, it is concluded that plasma antioxidant defense system is insufficient and impaired in BD. Behçet's disease; plasma myeloperoxidase (MPO); glutathione peroxidase (GSH-Px); malondialdehyde (MDA); plasma antioxidants
\end{abstract}

Behçet's disease (BD) was first described in 1937 by a Turkish dermatologist, Hulusi Behçet, as a triad of uveitis, aphthous lesions of the oral mucosa and genital ulcerations (Behçet 1937). Recent studies have shown that the disease is a multisystem disorder that affects skin, mucous membranes, eyes, joints, central nervous system and blood vessels. Vasculitis is also defined as a major feature of the disease (Jorizzo et al. 1985). The etiology of this unusual disease remains obscure. Although bacterial or viral infections, genetic, environmental and immunologic factors have been implicated in the pathogenesis of the illness, the exact cause is still unknown (Jorizzo et al. 1985; O'Duffy 1990).

On the other hand, investigations have shown that various functions of polymorphonuclear cells (PMN) in peripheral blood, such as chemotaxis, phagocytosis, lysosomal enzyme activities, and also superoxide radical anion $\left(\mathrm{O}_{2}{ }^{-}\right)$ generation, increased in $\mathrm{BD}$. Consequently, these stimulated neutrophil functions

Received December 6, 1994; revision accepted for publication May 12, 1995. 
have been considered to be correlated to the pathogenesis of BD (Matsumura and Mizushima 1975; Yamada et al. 1981; Niwa et al. 1982; Fujita et al. 1984). Especially, oxidative species, including $\mathrm{O}_{2}^{-}$, have been proposed as possible mediators for tissue damage associated with BD (Yamada et al. 1981; Niwa et al. 1982).

These earlier observations are increasingly supported with recent studies (Niwa and Mizushima 1990; Pronai et al. 1990, 1991). Further, it is observed that there are alterations in activities of enzymes consisting of oxidant/antioxidant system of PMN leucocytes in $\mathrm{BD}$ and suggested that increased levels of oxygen free radicals, as a result of these alterations, may play a role in tissue damage in BD (Doğan et al. 1994).

In view of the findings mentioned above, the present study was planned to examine whether the plasma antioxidant defense system is impaired in $\mathrm{BD}$, and if so, whether there is any correlation between the plasma antioxidant defense system and PMN cells. We, therefore, determined myeloperoxidase (MPO; E.C. 1.11.1.7) and glutathione peroxidase (GSH-Px; E.C. 1.11.1.9) activities, and thiol $(\mathrm{SH})$, transferrin (TF) ceruloplasmin $(\mathrm{Cp})$, copper $(\mathrm{Cu})$, selenium $(\mathrm{Se})$ levels along with lipid peroxidation in plasma of patients with $\mathrm{BD}$.

\section{Methods}

Subjects. The present study was performed on patients with BD attending Ophthalmology and Dermatology Departments of Erciyes University, Research Hospital. Twenty-four patients, 20 male and 4 female, were diagnosed as complete type according to the criteria of International Study Group (ISG) (International Study Group for Behçet's Disease 1990). The ages of the patients ranged from 20 up to 40 years (mean age, $28.54 \pm 7.70$ years) and the duration of the disease from first symptoms was between 1 and 18 years (average 6.04 \pm 4.24 years). At the time of the study, patients were in acute stage of the disease with no systemic medication.

Thirty apparently healthy medical students and hospital personnel (25 male and 5 female), age-matched, were also included as controls in the present study.

Biochemical procedure. Heparinized blood obtained from patients and controls was kept at $4^{\circ} \mathrm{C}$ for $30 \mathrm{~min}$, then centrifuged at $1500 \times g$ for $15 \mathrm{~min}$. Plasma was carefully aspirated off, leaving the buffy coat and packed erythrocytes, and stored at $-70^{\circ} \mathrm{C}$ until analysis. Only plasma $\mathrm{SH}$ measurements were carried out on the same day.

$\mathrm{SH}$ concentrations in plasma were estimated by the method of Koster et al. (1986) using the thiol-disulphide interchange reaction between 5, 5'-dithiobis (2-nitrobenzoic acid) (DTNB) and thiols. Plasma malondiadehyde (MDA, a breakdown product of lipid peroxidation) levels were assayed by a spectrophotometric method (Wong et al. 1987) which was partly modified in our laboratory, without the high pressure chromatography seperation step. Briefly, after 
boiling at $100^{\circ} \mathrm{C}$ for $60 \mathrm{~min}$, and cooling, $n$-butanol was added into the tubes and mixed vigorously. The butanol phase was seperated by centrifugation and absorbance was measured at $532 \mathrm{~nm}$. The CV value of this modified method was found to be $3.2 \%$. Plasma TF levels were determined by immunoturbidimetric assay using a kit from Bayer Diagnostics (Code 6805, Ames, Orcq-Tournai, Belgium). Plasma $\mathrm{Cp}$ values were measured by the method based on ceruloplasmin-catalyzed oxidation of $p$-phenylenediamine (Sunderman and Nomoto 1970).

Plasma $\mathrm{Cu}$ and Se levels were assayed by atomic absorbtion spectrometry (Z-8000, Hitachi, Tokyo), with a Zeeman background correction. Flame technique, with standards made in $10 \%$ glycerol; and graphite furnace technique, with palladium modifier and pyrolitically coated graphite tubes were used for $\mathrm{Cu}$ (Tietz 1986); and Se (Jacobson and Lockitch 1988), respectively.

GSH-Px activity was measured by the coupled assay described by Paglia and Valentine (1967) using $\mathrm{H}_{2} \mathrm{O}_{2}$ as substrate. The assay kinetics were calculated by using a molar absorbtivity of NADPH of $6.22 \times 10^{-3} \mathrm{M}^{-1} \mathrm{~cm}^{-1}$ at $340 \mathrm{~nm}$. One unit of enzyme activity was defined as the number of $\mu \mathrm{mol}$ of NADPH oxidized per liter of plasma per minute (Paglia and Valentine 1967). MPO activity was determined by a modification of the $o$-dianisidine method (Goto et al. 1992). One unit of MPO was defined as that degrading one $\mu \mathrm{mol}$ of $\mathrm{H}_{2} \mathrm{O}_{2}$ per min at $25^{\circ} \mathrm{C}$. A molar extinction coefficient of $1.13 \times 10^{4}$ of oxidized $o$-dianisidine was used for the calculation (Goto et al. 1992). Enzyme activities, GSH-Px and MPO, were expressed as U/liter.

Statistical analysis. All measurements were performed in duplicate, and values were expressed as the mean \pm s.D. The significance of the differences between means from patients and controls was calculated by the Student's $t$-test. Correlation analyses were also performed between parameters measured in BD patients. The level of significance was accepted as $p<0.05$.

\section{RESULTS}

The data of the present study are presented in Table 1. When compared to controls, there were significant increases in plasma levels of MDA $(p<0.001)$, Cp $(p<0.001), \mathrm{Cu}(p<0.01)$, and also in plasma MPO activity $(p<0.001)$ in patients with $\mathrm{BD}$. On the other hand, plasma TF $(p<0.001)$, SH $(p<0.001)$, Se $(p<$ $0.001)$ levels and also GSH-Px activity $(p<0.001)$ were found to be lower in BD patients then those in controls.

When correlation analyses were performed in patient group, there were positive and significant correlations between MDA-Cp $(p<0.05), \mathrm{MDA}-\mathrm{Cu}(p<$ $0.05)$, MDA-MPO $(p<0.001)$, MPO-Cp $(p<0.05)$, GSH-Px-Se $(p<0.001)$, Cp-Cu $(p<0.001)$ and TF-SH $(p<0.05)$ parameters; but negative and significant correlations between MPO-TF $(p<0.05)$ and Cp-TF $(p<0.05)$ parameters. However, no correlation was observed among the other parameters. Only significant corre- 
TABLE 1. Malondialdehyde, thiol, transferrin, ceruloplasmin, copper and selenium levels, and glutathione peroxidase and myeloperoxidase activities in plasma of patients with Behçet's disease and controls

\begin{tabular}{lrrr}
\hline \multicolumn{1}{c}{ Parameters } & \multicolumn{1}{c}{$\begin{array}{c}\text { BD patients } \\
(n=24)\end{array}$} & $\begin{array}{c}\text { Controls } \\
(n=30)\end{array}$ & $p$ Value \\
\hline Malondiadehyde (MDA; $\mu$ mol/liter) & $4.03 \pm 0.76$ & $1.96 \pm 0.35$ & $<0.001$ \\
Thiol (SH; $\mu$ mol/liter) & $457.20 \pm 66.44$ & $663.52 \pm 74.68$ & $<0.001$ \\
Transferrin (TF; g/liter) & $1.78 \pm 0.46$ & $2.74 \pm 0.46$ & $<0.001$ \\
Ceruloplasmin (Cp; g/liter) & $0.48 \pm 0.10$ & $0.31 \pm 0.06$ & $<0.001$ \\
Copper (Cu; mg/liter) & $1.28 \pm 0.28$ & $1.07 \pm 0.16$ & $<0.01$ \\
Selenium (Se; $\mu /$ liter) & $131.66 \pm 46.96$ & $196.0 \pm 46.30$ & $<0.001$ \\
Glutathione peroxidase (GSH-Px; U/liter) & $179.34 \pm 32.96$ & $405.81 \pm 60.11$ & $<0.001$ \\
Myeloperoxidase (MPO; U/liter) & $279.63 \pm 48.12$ & $69.80 \pm 10.74$ & $<0.001$ \\
\hline
\end{tabular}

Values are mean \pm s.D.

$n$, The number of subjects.

TABLE 2. Correlation analysis between parameters measured in patients with Behçet's disease

\begin{tabular}{lccl}
\hline Parameters & $\mathrm{r}$ & $\mathrm{y}=\mathrm{ax}+\mathrm{b}$ & $p$ Value \\
\hline MDA-Cp & 0.500 & $2.22 \mathrm{x} \pm 3.75$ & $<0.05$ \\
MDA-Cu & 0.461 & $2.46 \mathrm{x} \pm 1.22$ & $<0.05$ \\
MDA-MPO & 0.650 & $1.15 \mathrm{x} \pm 0.01$ & $<0.001$ \\
MPO-Cp & 0.495 & $0.18 \mathrm{x} \pm 0.001$ & $<0.05$ \\
MPO-TF & -0.499 & $3.13 \mathrm{x}-0.004$ & $<0.05$ \\
Cp-Cu & 0.868 & $0.09 \mathrm{x} \pm 0.31$ & $<0.001$ \\
Cp-TF & -0.450 & $2.77 \mathrm{x}-2.06$ & $<0.05$ \\
TF-SH & 0.465 & $339.78 \mathrm{x} \pm 66.15$ & $<0.05$ \\
CSH-Px-Se & 0.870 & $-90.63 \mathrm{x} \pm 0.87$ & $<0.001$ \\
\hline
\end{tabular}

lations mentioned above are presented in Table 2.

\section{Discussion}

With increasing frequency, the human neutrophil is being implicated as a mediator of tissue-destructive events in inflammatory diseases (Fantone and Ward 1985; Weiss 1989). Activated neutrophils produce more reactive oxygen species (ROS) in inflammatory conditions. ROS can react with all biological substances, especially, polyunsaturated fatty acids (Klebanoff 1988); reactions with these cell membrane constituents lead to lipid peroxidation (Fantone and Ward 1985; Weiss 1989). It has also been speculated that excess lipid peroxides formed in tissues are released into the blood plasma (Kasama et al. 1988). In the present study, the enhanced plasma MDA levels, an index of lipid peroxidation, were observed in our 
patients. Although we could not find a previous report about lipid peroxidation in $\mathrm{BD}$, it might be expected and explained in various ways. Indeed, functional abnormalities including excess $\mathrm{O}_{2}{ }^{-}$generation in the neutrophils of $\mathrm{BD}$ patients have been reported (Niwa et al. 1982; Fujita et al. 1984). Hence, activated neutrophils could damage biological targets through lipid peroxidation in BD. In addition, superoxide scavenging activity (SSA) of PMN has been found to be lower in BD patients (Pronai et al. 1991), and also shown that there were strong negative correlations between SSA of PMN and their $\mathrm{O}_{2}{ }^{-}$release, and disease activity (Pronai et al. 1991). According to Pronai et al. (1991), the enhanced $\mathrm{O}_{2}{ }^{-}$ generation by PMN in vivo may be responsible for the decreased SSA of PMN in $\mathrm{BD}$ and $\mathrm{PMN}$ might be able to release more $\mathrm{O}_{2}{ }^{-}$in tissues. In the study performed in our University, decreased MPO, SOD, catalase and GSH-Px activites, and increased NADPH-oxidase activity in PMN cells were observed in BD patients (Doğan et al. 1994). These findings support those of Pronai et al. $(1990,1991)$ and clearly indicate that there is significant decrease in SSA of PMN due to decreased enzyme activities in the antioxidant system of PMN in BD. Consequently, more increase in $\mathrm{O}_{2}^{-}$generation may lead to more lipid peroxidation in tissues in BD.

On the other hand, activated neutrophils can release substantial amounts of the enzyme MPO into the extracellular fluids, together with $\mathrm{O}_{2}{ }^{-}$and $\mathrm{H}_{2} \mathrm{O}_{2}$ release, after respiratory burst (Weiss 1989). MPO can generate extracellular hypochlorous acid (HOCI) that rapidly attacks biological molecules and participates in the generation of chloramines (Klebanoff 1988). Each of these compounds found in plasma has been shown to possess significant cytotoxic activity resulting in lipid peroxidation (Fantone and Ward 1985; Weiss 1989). In the present study, we observed a statistically significant increase in MPO activity in plasma of BD patients compared to controls, and also a positive correlation between MPO and MDA levels in patients. According to these findings, excessive release of MPO by PMN into the plasma may occur during the acute stage of the disease. These findings also confirm the studies indicating a decrease in MPO activity of PMN cells obtained from patients with BD (Yamada et al. 1981; Doğan et al. 1994).

Besides decreased SSA of PMN, SSA of plasma was also found to be lower in $\mathrm{BD}$ patients and it shows an inverse correlation with disease activity (Pronai and Arimori 1991). In a previous study we have also found decreased total plasma antioxidant activity in patients with BD (Köse et al. 1993). SOD, catalase and GSH-Px, known as the major primary intracellular antioxidant defense, contribute little to regulate the concentration of oxygen metabolites in extracellular fluids. However, primary antioxidant defenses of normal plasma are mainly concerned with the prevention of transitional metal participation in free radical reactions such as lipid peroxidation (Halliwell and Gutteridge 1990a). Therefore, iron-binding and iron-oxidizing proteins, such as $\mathrm{TF}$ and $\mathrm{Cp}$, respectively, are suggested as primary antioxidants of human plasma (Gutteridge and Quinlan 
1993).

Although several antioxidant mechanisms have been suggested to explain the proposed protective actions of $\mathrm{Cp}$ in iron metabolism, the most biologically important function of $\mathrm{Cp}$ is its ferroxidase activity. $\mathrm{Cp}$ oxidizes $\mathrm{Fe}^{+2}$ to $\mathrm{Fe}^{+3}$ and facilitates the binding of iron to TF. Thus, ferric ions are tightly bound to and transported by TF (Halliwell and Gutteridge 1990a, b). Therefore, Cp together with TF inhibit iron-ion dependent $\mathrm{OH} \bullet$ formation from $\mathrm{H}_{2} \mathrm{O}_{2}$ and lipid peroxidation. In the present study, the plasma level of $\mathrm{Cp}$ was found to be higher, but TF lower in BD patients than those in healthy controls. In addition we observed significant positive correlations between MPO-Cp, and MDA-Cp levels, whereas negative correlations between MPO-TF, and Cp-TF levels were found in BD patients. According to our findings, elevated Cp and decreased TF levels may be related to the infiammation associated with the disease. Since, in inflammatory situations, plasma levels of $\mathrm{Cp}$, known as an acute phase reactant, are increased (DiSilvestro 1989; Muntane et al. 1993), whereas TF, known as a negative acute phase reactant (Tietz 1986), is consumed (Ahmadzadeh et al. 1989). Hence, the low TF concentration in BD patients could contribute to a failure in the plasma antioxidant defense. This is further supported with elevated plasma MPO activity, which was found to be correlated positively with $\mathrm{Cp}$ and negatively with TF. Since, it is shown that MPO released by stimulated neutrophils may impair the ability of $\mathrm{TF}$ to take up the iron released from ferritin (Monteiro and Winterbourn 1988). On the other hand, elevated Cp observed in BD patients may be a protective response to an increase in circulating unbound $\mathrm{Fe}^{+2}$. However, the increase in $\mathrm{Cp}$ levels may not be sufficient in protecting tissues from oxidative damage, as seen in the present study. Further, a negative correlation between $\mathrm{Cp}$ and TF levels observed in BD patients was an important finding, which shows that incorporation between TF and $\mathrm{Cp}$ functions in normal conditions may impair in $\mathrm{BD}$.

It is also shown that inflammation, an acute phase stress, alters $\mathrm{Cu}$ metabolism, and $\mathrm{Cu}$ levels are elevated in plasma (Di Silvestro 1989). Cu levels presented here are in agreement with the studies reporting high $\mathrm{Cu}$ levels in BD (Shimizu et al. 1979; Cengiz and Gürbayrak 1988; Köse et al. 1993; Doğan et al. 1994). In addition, we observed significant positive correlations between $\mathrm{Cp}-\mathrm{Cu}$, and MDA-Cu levels in plasma of BD patients. Recently it is shown that oxidants generated from the MPO system may be responsible for oxidative inactivation of the $\mathrm{Cu}$-binding sites of $\mathrm{Cp}$, and possibly because of the release of $\mathrm{Cu}$ ions from $\mathrm{Cp}$, lipid peroxidation is enhanced by stimulated neutrophils and ferritin (Abdalla et al. 1992). Although $\mathrm{Cu}$ metabolism in $\mathrm{BD}$ is not completely understood, it may be thought that high $\mathrm{Cu}$ levels may stimulate lipid peroxidation by enhancing more $\mathrm{OH} \bullet$ formation and contribute to further increase in lipid peroxidation and also tissue damage seen in $\mathrm{BD}$.

It is speculated that plasma $\mathrm{SH}$ groups act as an important extracellular 
scavenger of peroxides and are also helpful in protecting the surrounding tissues (Hall et al. 1984). Critical SH groups on cell membranes protect proteins against oxidative damage by MPO-derived HOCI (Weiss 1989), while they are consumed. The reduced plasma $\mathrm{SH}$ levels have also been attributed to the actions of $\mathrm{H}_{2} \mathrm{O}_{2}$ (Hall et al. 1984), and transition metal ions (Halliwell and Gutteridge 1990b) promote oxidation of $\mathrm{SH}$ groups; further $\mathrm{Cp}$ is a specific oxidase for $\mathrm{SH}$ containing small molecules (Rae et al. 1986). In the present study, decreased plasma SH levels were observed in BD patients; and there was a positive correlation between $\mathrm{SH}$ and TF levels. ROS generated by stimulated neutrophils, and elevated $\mathrm{Cp}$ and $\mathrm{Cu}$ levels may diminish the amount of free $\mathrm{SH}$ groups in plasma of patients with $\mathrm{BD}$, due to the reasons mentioned above. In addition, the decreases in $\mathrm{SH}$ along with TF levels clearly indicate that plasma antioxidant defense mechanisms may be both impaired and insufficient in BD.

Fatty acid hydroperoxides, the primary products of enzymatic and nonenzymatic oxygenation of unsaturated fatty acids, intermediates in the arachidonic acid (AA) cascade, react with transition metal complexes and metalloproteins to generate highly toxic free radicals. Excess lipid peroxides formed in tissues are released into the plasma and reduced to the corresponding alcohols by plasma GSH-Px, shown to be different from the intracellular enzyme (Maddipati and Marnett 1987; Kasama et al. 1988). On the other hand, GSH-Px may be inactivated during oxidative stress (Blum and Fridovich 1985); $\mathrm{Cu}^{+2}$ (Takahashi et al. 1987) and toxic ligands such as MDA (Arshad et al. 1991) could partially inhibit plasma GSH-Px activity. Significant decreases in plasma GSH-Px activities of patients with $\mathrm{BD}$ presented here were also been found in patients with certain skin disorders, including vasculitis (Juhlin et al. 1982). Since, BD is thought to be the result of vasculitis (Jorizzo et al. 1985) and an imbalance between AA metabolites is accepted to be responsible for inflammation and vasculitis, as now seen in $\mathrm{BD}$ (Bozkurt et al. 1989); the decrease in plasma GSH-Px may be related to hydroperoxide pathology. Also excess $\mathrm{O}_{2}{ }^{-}$generation by $\mathrm{PMN}$ cells, and the presence of high MDA and $\mathrm{Cu}$ levels seen in $\mathrm{BD}$ may be responsible for the decreased GSH-Px levels in plasma of $\mathrm{BD}$ patients.

Apart from these, Se deficiency may be a factor for low GSH-Px levels, because, Se, an essential trace element, is an essential component of GSH-Px (Maddipati and Marnett 1987). Se serves to catalyze the reduction of hydroperoxides produced from oxidized species (Lockitch 1989). Se has also shown to have antiproliferative, antiinflammatory, antiviral and immune modulating effects (O'dell et al. 1991). Since inflammation plays a central part in the expression of $\mathrm{BD}$, these Se effects are of interest. Plasma Se levels were found to be lower in BD patients (Delilbasi et al. 1991; Doğan et al. 1993) and suggested that a deficiency in Se impedes the humoral immune response; and it may play an important role in the etiology or prognosis of some inflammatory conditions, and of signs and symptoms of pathological disorders, such as BD (Delilbasi et al. 1991). 
In the present study, we confirmed that plasma Se levels in patients with $\mathrm{BD}$ are lower than in healthy subjects. Low Se levels may be a sign of depletion of stores or redistribution of total body Se. Therefore, a defective regulation of GSH-Px together with Se could account for some pathological features of BD. The presence of positive correlation between GSH-Px and Se levels observed in our patients may potentiate these suggestions mentioned above.

To our current knowledge, in BD patients, plasma MPO and GSH-Px activities, and MDA, Cp, TF, SH levels were measured for the first time in our University. These findings are of interest and may help the literature related to the pathogenesis and prognosis of $\mathrm{BD}$.

In conclusion, the findings presented here strongly indicate that plasma antioxidant defense mechanisms are insufficient and impaired in BD.

\section{References}

1) Abdalla, D.S.P., Campa, A. \& Monteiro, H.P. (1992) Low density lipoprotein oxidation by stimulated neutrophils and ferritin. Atherosclerosis, 97, 149-159.

2) Ahmadzadeh, N., Shingu, M. \& Nabunagam, M. (1989) Iron-binding proteins and free iron in synovial fluids of rheumatoid arthritis patients. Clin. Rheumatol., 8, 345351.

3) Arshad, M.A.Q., Bhadra, S., Cohen, R.M. \& Subbiah, M.T.R. (1991) Plasma lipoprotein peroxidation potential: A test to evaluate individual susceptibility. Clin. Chem., 37, 1756-1758.

4) Behçet, H. (1937) Über rezidiverende aphthöse, durch ein Virus verursachte Geschwüre am Mund, am Auge und an den Genitalien. Dermatol. Wochenschr, 105, 11521157.

5) Blum, J. \& Fridovich, I. (1985) Inactivation of glutathione peroxidase by superoxide radical. Arch. Biochem. Biophys., 240, 500-508.

6) Bozkurt, M., Gürer, M.A., Gülekon, A., Keskin, N. \& Ercan, S. (1989) Arachidonic acid metabolites in Behçet's disease. Int. J. Dermatol., 28, 141-142.

7) Cengiz, K. \& Gürbayrak, F. (1988) Serum zinc, copper and magnesium in Behçet's disease. Mater. Med. Pol., 20, 190-193.

8) Delilbasi, E., Turan, B., Yücel, E., Sasmaz, R., Isimer, A. \& Sayal, A. (1991) Selenium and Behçet's disease. Biol. Trace. Element. Res., 28, 21-25.

9) DiSilvestro, R.P. (1989) Effects of inflammation on copper antioxidant enzyme levels. Adv. Exp. Med. Biol., 258, 252-258.

10) Doğan, P., Doğan, M. \& Klockenkämper, R. (1993) Determination of trace elements in blood serum of patients with Behçet disease by total reflexion $\mathrm{x}$-ray fluorescence analysis. Clin. Chem., 39, 1037-1041.

11) Doğan, P., Tanrikulu, G., Soyuer, Ü. \& Köse, K. (1994) Oxidative enzymes of polymorphonuclear leucocytes and plasma fibrinogen, ceruloplasmin and copper levels in Behçet's disease. Clin. Biochem., 27, 413-418.

12) Fantone, J.C. \& Ward, P.A. (1985) Polymorphonuclear leukocyte mediated cell and tissue injury: Oxygen metabolites and their relationship to human disease. Human. Pathol., 16, 973-978.

13) Fujita, Y., Yamada, M., Asai, K. \& Mimura, Y. (1984) Generation of superoxide radical by neutrophils in Behçet's disease. Jpn. J. Ophthalmol., 3, 221-226.

14) Goto, H., Wu, G.S., Chen, F., Kristeva, M., Sevanian, A. \& Rao, Na. (1992) Lipid peroxidation in experimental uveits: Sequental studies. Curr. Eye Res., 6, 489-499.

15) Gutteridge, J.M.C. \& Quinlan, G.J. (1993) Antioxidant protection against organic 
and inorganic oxygen radicals by normal human plasma: The important primary role of iron-binding and iron-oxidising proteins. Biochem. Biophys. Acta, 1156, 114-150.

16) Halliwel, B. \& Gutteridge, J.M.C. (1990a) The antioxidants of human extracellular fluids. Arch. Biochem. Biophys., 280, 1-8.

17) Halliwell, B. \& Gutteridge, J.M.C. (1990b) Role of free radicals and catalytic metal ions in human disease: An overview. Methods Enzymol., 186, 1-85.

18) Hall, N.D., Maslen, C.L. \& Blake, D.R. (1984) The oxidation of serum sulphydryl groups by hydrogen peroxide secreted by stimulated phagocytic cells in rheumatoid arthritis. Rheumatol. Int., 4, 35-38.

19) International Study Group for Behcet's Disease (1990) Criteria for diagnosis of Behcet's disesase. Lancet, 335, 1078-1080.

20) Jacobson, B.E. \& Lockitch, G. (1988) Direct determination of selenium in serum by graphite-furnace atomic absorbtion spectrometry with deuterium background correction and a reduced palladium modifier: Age specific reference ranges. Clin. Chem., 34, 709-714.

21) Jorizzo, J.L., Solomon, A.R. \& Cavallo, T. (1985) Behcet's syndrome. Arch. Pathol. Lab. Med., 109, 747-751.

22) Juhlin, I., Edqvist, I.E., Ekman, L.G., Ljunghall, K. \& Olsson, M. (1982) Blood glutathione peroxidase levels in skin diseases: Effect of selenium and vitamin $\mathrm{E}$ treatment. Acta Dermatovener. Venereol. (Stockh.), 62, 211-214.

23) Kasama, T., Kobayashi, K., Sekine, F., Negishi, M., Ide, H., Takahashi, T. \& Niwa, Y. (1988) Follow-up study of lipid peroxides, superoxide dismutase and glutathione peroxidase in the synovial membrane serum and liver of young and old mice with collagen-induced arthritis. Life. Sci., 43, 1887-1896.

24) Klebanoff, S.J. (1988) Phagocytic cells: Products of oxygen metabolism. In: Inflammation: Basic Principles and Clinical Correlates, edited by J.I. Gallin, I.M. Goldstein \& R. Synderman, Raven Press, New York, pp. 391-444.

25) Koster, J.F., Biemond, P. \& Swaat, A.J.G. (1986) Intracellular and extracellular sulphydril levels in rheumatoid arthritis. Ann. Rheum. Dis., 45, 44-46.

26) Köse, K., Dogan, P., Ascioglu, M., Erkilic, K. \& Ascioglu, Ö. (1993) Antioxidant potential of plasma in Behçet's disease. Erciyes Med. J., 15, 350-356.

27) Lockitch, G. (1989) Selenium: Clinical significance and analytical concepts. C.R. C.Lab.Sci., 27, 483-541.

28) Maddipati, K.R. \& Marnett, L.J. (1987) Characterization of the major hydroperoxide reducing activity of human plasma. J. Biol. Chem., 262, 17398-17403.

29) Matsumura, N. \& Mizushima, Y. (1975) Leucocyte movement and colchicine treatment in Behçet's disease. Lancet, 2, 813-817.

30) Monteiro, H.P. \& Winterbourn, C.C. (1988) The superoxide dependent iron transfer from ferritin to transferrin and lactoferrin. Biochem. J., 256, 923-929.

31) Muntane, J., Puig-Parellda, P., Fernandez, Y., Mitjavila, S. \& Mitjavila, M.T. (1993) Antioxidant defenses and its modulation by iron in carrageenan-induced inflammation in rats. Clin. Chim. Acta, 214, 185-193.

32) Niwa, Y. \& Mizushima, Y. (1990) Neutrophill-potentiating factors released from stimulated lymphocytes special referance to the increase in neutrophil-potentiating factors from streptococcus-stimulated lymphocytes of patients with Behçet's disease. Clin. Exp. Immunol., 79, 353-360.

33) Niwa, Y., Miyake, S., Sakane, T., Shingu, M. \& Yokoyama, M. (1982) Auto-oxidative damage in Behçet's disease-endothelial cell damage following the elevated oxygen radicals generated by stimulated neutrophil. Clin. Exp. Immunol., 49, 247-255.

34) O'dell, J.R., Lemley-Gillespie, S., Palmer, W.R., Weaver, A.l., Moore, G.F. \& Klassen, L.W. (1991) Serum selenium concentrations in rheumatoid arthritis. Ann. Rheum. Dis., 50, 376-381.

35) O'Duffy, JD. (1990) Behçet's syndrome. N. Engl. J. Med., 322, 326-327. 
36) Paglia, D.E. \& Valentine, W.N. (1967) Studies on the quantitative and qualitative characterization of erythrocyte glutathione peroxidase. J. Lab. Clin. Med., 70, 158169.

37) Pronai, L. \& Arimori, S. (1991) BG-104 enhances the decreased plasma superoxide scavenging activity in patients with Behçet's disease, Sjogren's syndrome or hematological malignancy. Biotherapy, 3, 365-371.

38) Pronai, L., Ichikawa, Y., Nakazawa, H. \& Arimori, S. (1990) Superoxide scavenging activity of leucocytes in rtheumatoid arthritis and Behçet's diseases. Tokai J. Exp. Clin. Med., 15, 93-97.

39) Pronai, L., Ichikawa, Y., Nakazawa, H. \& Arimori, S. (1991) Enhanced superoxide generation and the decreased superoxide scavenging activity of peripheral blood leukocytes in Behçet's disease-effects of colchicine. Clin. Exp. Rheumatol., 9, 227233.

40) Rae, K.J, Mackay, C.N.N., McNeil, C.J., Brown, D.H., Smith, W.E., Lewis, D. \& Capell, H.A. (1986) Early and late changes in sulphydril group and copper protein concentrations and activities during drug treatment with aurothiomalate and auronofin. Ann. Rheum. Dis., 45, 839-846.

41) Shimizu, K., Ishikawa, S., Miyata, M., Yoshida, H. \& Kuba, H. (1979) Relationship between the changes of serum $\mathrm{Cu}$ levels and ocular attacks in Behçet's disease. Excerpta Medica (Amsterdam), 61-65.

42) Sunderman, F.W. \& Nomoto, S. (1970) Measurement of human serum ceruloplasmin by its p-phenylene diamine oxidase activity. Clin. Chem., 16, 903-910.

43) Takahashi, K., Avissar, N.,Whitin, J. \& Cohen, H. (1987) Purification and characterization of human plasma glutathione peroxidase: A selenoglycoprotein distinct from the known cellular enzyme. Arch. Biochem. Biophys., 256, 677-686.

44) Tietz, N.W. (1986) Textbook of Clinical Chemistry, W.B. Saunders Co., Philadelphia, pp. 559-563, pp. 981-985.

45) Weiss, S.J. (1989) Tissue destruction by neutrophils. N.Engl. J. Med., 320, 365376.

46) Winterbourn, CC., Monteiro, HP. \& Galilee, CF. (1990) Ferritin dependent lipid peroxidation by stimulated neutrophil. Biochim. Biophys. Acta, 1055, 179-186.

47) Wong, S.H.Y., Knight, J.A., Hopfer, S.M., Zaharia, O., Leach, C.N. \& Sunderman, F.W. (1987) Lipoperoxides in plasma as measured by liquid-chromatographic seperation of malondialdehyde-thiobarbituric acid adduct. Clin. Chem., 33, 214-220.

48) Yamada, M., Mimura, Y., Watanabe, K., Yuasa, T. \& Murai, Y. (1981) Neutrophil lysosome enzyme activities in patients with Behçet's disease. In: Behçet's Disease, edited by G. Inaba, Jpn. Med. Res. Found Pub., Tokyo, pp. 259-267. 